Clinical techniques and TeChNologies

\title{
Preliminary experience with 4K ultra-high definition endoscope: analysis of pros and cons in skull base surgery
}

\section{Esperienza preliminare con endoscopio 4K: analisi di pro e contro nella chirurgia del basicranio}

\author{
M. RIGANTE', G. LA ROCCA², L. LAURETTI², G.Q. D’ALESSANDRIS², A. MANGIOLA², C. ANILE², A. OLIVI², \\ G. PALUDETTI \\ ${ }^{1}$ Institute of Otorhinolaryngology, Catholic University School of Medicine, Rome, Italy; ${ }^{2}$ Institute of Neurosurgery, \\ Catholic University School of Medicine, Rome, Italy
}

\section{SUMMARY}

During the last two decades endoscopic skull base surgery observed a continuous technical and technological development 3D endoscopy and ultra High Definition (HD) endoscopy have provided great advances in terms of visualisation and spatial resolution. Ultra-high definition (UHD) 4K systems, recently introduced in the clinical practice, will shape next steps forward especially in skull base surgery field. Patients were operated on through transnasal transsphenoidal endoscopic approaches performed using Olympus NBI 4K UHD endoscope with a $4 \mathrm{~mm} 0^{\circ}$ Ultra Telescope, $300 \mathrm{~W}$ xenon lamp (CLV-S400) predisposed for narrow band imaging (NBI) technology connected through a camera head to a high-quality control unit (OTV-S400 - VISERA 4K UHD) (Olympus Corporation, Tokyo, Japan). Two screens are used, one 31" Monitor - (LMD-X310S) and one main ultra-HD 55" screen optimised for UHD image reproduction (LMD-X550S). In selected cases, we used a navigation system (Stealthstation S7, Medtronic, Minneapolis, MN, US). We evaluated 22 pituitary adenomas (86.3\% macroadenomas; $13.7 \%$ microadenomas). 50\% were not functional (NF), 22.8\% GH, 18.2\% ACTH, 9\% PRL-secreting. Three of 22 were recurrences. In $91 \%$ of cases we achieved total removal, while in 9\% near total resection. A mean follow-up of 187 days and average length of hospitalisation was $3.09 \pm 0.61$ days. Surgical duration was $128.18 \pm 30.74$ minutes. We experienced only 1 case of intraoperative low flow fistula with no further complications. None of the cases required any post- or intraoperative blood transfusion. The visualisation and high resolution of the operative field provided a very detailed view of all anatomical structures and pathologies allowing an improvement in safety and efficacy of the surgical procedure. The operative time was similar to the standard 2D HD and 3D procedures and the physical strain was also comparable to others in terms of ergonomics and weight.

KEY WORDS: 4K・Ultra-high definition $\bullet$ Endoscopy $\bullet$ Skull base $\bullet$ Endoscopic sinus surgery

\section{RIASSUNTO}

Negli ultimi venti anni la chirurgia endoscopica del basicranio ha osservato continui sviluppi tecnici e tecnologici. L'endoscopia 3D e l' alta definizione (HD) 4 K hanno fornito grandi vantaggi in termini di visualizzazione e di risoluzione spaziale. L'ultra HD $4 K$, recentemente introdotta nella pratica clinica, determinerà i prossimi passi soprattutto nella chirurgica endoscopica del basicranio. I pazienti sono stati operati attraverso un approccio transnasale transfenoidale endoscopico, utilizzando un endoscopio Olympus NBI 4K UHD con ottica 4 $\mathrm{mm} 0^{\circ}$ Ultra Telescope, lampada allo xeno $300 \mathrm{~W}$ (CLV-S400) predisposto per la tecnologia narrow band imaging (NBI) collegato con una videocamera ad un alta qualità unità di controllo (OTV-S400 - VISERA 4K UHD) (Olympus, Tokyo, Giappone). Due schermi, un 31 “Monitor - (LMD-X310S) e quello principale ultra-HD 55" a pollici ottimizzati per la riproduzione immagini UHD (LMD-X550S). In casi selezionati abbiamo usato un sistema di navigazione (Stealthstation S7, Medtronic, Minneapolis, MN, Stati Uniti). Abbiamo valutato 22 adenomi ipofisari (86,3\% macroadenomi; $13,7 \%$ microadenomi). Il 50\% non erano secernenti (NS), 22,8\% GH, 18,2\% ACTH, 9\% PRLsecernenti. 3/22 erano recidive. Nel $91 \%$ dei casi abbiamo raggiunto la rimozione totale, mentre nel $9 \%$ la resezione subtotale. Un followup medio di 187 giorni, durata media del ricovero era 3,09 \pm 0,61 giorni. Tempo chirurgico 128,18 \pm 30,74 minuti. Abbiamo avuto solo 1 caso di fistola intraoperatoria a basso flusso senza ulteriori complicazioni nel follow up. Il 100\% dei casi non ha richiesto emotrasfusione. La visualizzazione e l'alta risoluzione del campo operatorio hanno fornito una vista dettagliata di tutte le strutture anatomiche e patologie e permesso il miglioramento della sicurezza e l'efficacia della procedura chirurgica. Il tempo operatorio è stato simile a quello dell'endoscopio $H D$ standard $2 D$ e 3D, come la fatica fisica era paragonabile ad altri in termini di ergonomicità e peso.

PAROLE CHIAVE: $4 K \bullet$ Endoscopia ultra HD $\bullet$ Chirurgia del basicranio $\bullet$ Chirurgia endoscopica nasosinusale 


\section{Introduction}

Transnasal endoscopic routes, especially for skull base surgery, are costantly evolving field. Nowadays, the introduction of new tools such as neuronavigation, UHD 4K endoscopy, 3D endoscopy together with many surgeon anatomical endevors are establishing the prominent role of transnasal endoscopic surgery ${ }^{2}$. $4 \mathrm{~K}$ UHD is a new equipment, released in 2015, that has been first used by ENT mainly in laryngoscopy. We report on the first preliminary surgical experience in skull base lesions in which we used a new ultra-high definition (UHD) 4K endoscope.

\section{Clinical techniques and technologies}

The UHD endoscopy system (Visera 4K UHD, Olympus) needs the usual set-up of the operating room (OR) for a combined neurosurgical/ENT procedure. The camera head (CH-S400, Olympus) is equipped with a $4 \mathrm{~mm}$ $0^{\circ}$ ultra telescope (WA96200A, Olympus), and $300 \mathrm{~W}$ xenon lamp (CLV-S400, Olympus). A high-quality control unit (OTV-S400, Olympus), which is also predisposed for narrow band imaging (NBI) technology, give us the final images through a dedicated ultra-HD 55" main screen (LMD-X550S, Olympus) optimised for endoscopic application and allowing correct reproduction of UHD images. A second ultra HD 31" screen is setted on the stand unit and can be useful for the second surgeon. A navigation system Stealthstation S7 (Medtronic, Minneapolis, MN, US). when needed, was setted up in our surgical theater. This surgical set-up was used in 22 patients operated by the same ENT/neurosurgical team performing a conventional bi-nostril transsphenoidal approach ${ }^{3}$ (Fig. 1). Once exposed, the adenoma was removed: microadenomas could be taken out utilising the extracapsular dissection technique; macroadenomas, instead, needed first intracapsular debulking and then extracapsular removal by meticulous microdissection from pituitary gland and diaphragm sellae. The dissection was completed without complications in nearly all cases. The nasal part was generally performed without any magnification with wide field, while the opening of the dura and removal of the pituitary pathology was usually performed holding the endoscope in a four hand technique and with 1.4 or 1.6 magnification to focus and gain detail on the sellar and parasellar structures. The bony and dural defect was closed with gelfoam (Johnson \& Johnson), autologous bone fragment harvested from the nasal septum and fibrin glue when necessary, the pedicled nasoseptal flap was added. The plasty was stabilised with fibrin glue. Bilateral nasal packs were kept in place for 48 hours. In the post-operative period, patients underwent nasal medications and clinico-radiological follow up at 3,6 and 12 months. We operated 22 pituitary adenomas, from grade zero to grade IV ac-
Table I. Demographic details of patients.

\begin{tabular}{lc} 
& \\
Male & Demographic details \\
Female & $31.8 \%$ \\
Age & $68.2 \%$ \\
\hline
\end{tabular}

cording to Knosp Classification (Table I). 22.8\% grade $0 ; 40.9 \%$ grade I; $18.1 \%$ grade II; $4.5 \%$ grade IIIA, $9.2 \%$ IIIB and $4.5 \%$ grade IV. $86.3 \%$ were macroadenomas, while $13.7 \%$ were microadenomas. Three of 22 were recurrences. $50 \%$ of cases were NS, $22.8 \% \mathrm{GH}, 18.2 \%$ ACTH and 9\% PRL. $31.8 \%$ were male, $68.2 \%$ female, mean age was $45.8 \pm 16.7$ years. Mean follow up 187 days and the average length of hospitalisation was 3.09 \pm 0.61 days. Surgical duration was $128.18 \pm 30.74 \mathrm{~min}-$ utes. We only experienced 1 case of intraoperative low flow fistula without sequelae during follow-up. We always

Table II. Surgical details of patients. Abbreviations: NF, non-functional; GH, growth hormone; PRL, prolactin; ACTH, adrenocorticotropic hormone.

\begin{tabular}{|c|c|}
\hline \multicolumn{2}{|c|}{ Surgical details } \\
\hline \multicolumn{2}{|c|}{ Size } \\
\hline Macro & $86.3 \%$ \\
\hline Micro & $13.70 \%$ \\
\hline \multicolumn{2}{|c|}{ Pathology } \\
\hline NF & $50.00 \%$ \\
\hline GH & $22.80 \%$ \\
\hline PRL & $9.00 \%$ \\
\hline ACTH & $18.20 \%$ \\
\hline \multicolumn{2}{|c|}{ Type of removal } \\
\hline Subtotal & $9 ., 00 \%$ \\
\hline Total & $91.00 \%$ \\
\hline \multicolumn{2}{|c|}{ Knosp } \\
\hline Grade 0 & $22.80 \%$ \\
\hline Grade I & $40.90 \%$ \\
\hline Grade ॥ & $18.10 \%$ \\
\hline Grade IIIA & $4.50 \%$ \\
\hline Grade IIIB & $9.20 \%$ \\
\hline Grade IV & $4.50 \%$ \\
\hline \multicolumn{2}{|c|}{ Naso-septal flap } \\
\hline Yes & $9.00 \%$ \\
\hline No & $91.00 \%$ \\
\hline \multicolumn{2}{|c|}{ CSF leak } \\
\hline Yes & 1 case \\
\hline No & 21 cases \\
\hline \multicolumn{2}{|c|}{ Surgical time } \\
\hline Mean (min) & $129, .18 \pm 30.74$ \\
\hline \multicolumn{2}{|c|}{ Follow-up } \\
\hline Mean (days) & $187.00 \pm 10.5$ \\
\hline \multicolumn{2}{|c|}{ Hospitalisation } \\
\hline Mean (days) & $3.09 \pm 0.61$ \\
\hline
\end{tabular}


arranged a rescue flap (vascular pedicled naso-septal flap) on one side, but used it in only $9 \%$ of cases (Table II). In terms of postoperative outcomes, in $91 \%$ of the cases we achieved total removal, while in $9 \%$ removal was near total. We observed no post operative CSF leak even if we had a low grade fistula during surgery. None of the cases required post- or intraoperative blood transfusion. The team did not experience any kind of technincal trouble during the procedures listed above; surgical time was the same of the standard 2D procedures. The new technology 4K UHD endoscope showed easy usage process and no complications such as image straining or shape diversion. We noted that it was fundamental to properly set the chromatic configuration, especially with red wavelengths, in order to have a good colour perception during bleeding in surgical procedures. The use of the dedicate rigid optics optimise the chromatic experience even if with a prope setting it is possible to use rigid scope of other brands previously available and routinely used. An ergonomic and low weight camera allowed us to have a reasonable physical stress given by camera holding that was very similar to other endoscopes and compared with the old system, even lighter.

\section{Discussion}

The continuous development and constant research of innovative technologies is mandatory in all third leves en- doscopic skull base centres. All new and updated visualisation technologies needs to be considered in this ever expanding field.

Obvioulsy good surgery needs good anatomical knowledges and skilled and experienced surgerons to have reasonable safety and good success margins. The visualisation systems play a significant and preeminent role in this context, mostly for endonasal endoscopic skull base surgery. Four thousand pixels on the longer axis give us a satisfactory visual resolution, more anatomical and well detailed information and an higher definition of the pathology under examination than the standard systems currently in use: it is almost 4 times more informations for frame compared to standard HD images. Structures like diaphragm sellae, pituytary gland, pituitary stalk and pathological lesion within the sellar space stood out clearly (Figs. 1, 2).

This new system did not require a learning curve because is not a $3 \mathrm{D}$ visualisation of the surgical field so it basically had the same landmarks of the other $2 \mathrm{D}$ high resolution devices.

The NBI equipment is a particular visual filter that can highlight the vascular trama of tissues, allowing us to properly distinguish the pituitary gland from the pathological tissue (Fig. 3); this should be taken into account especially for oncologic cases, but in this field need further study and experience.

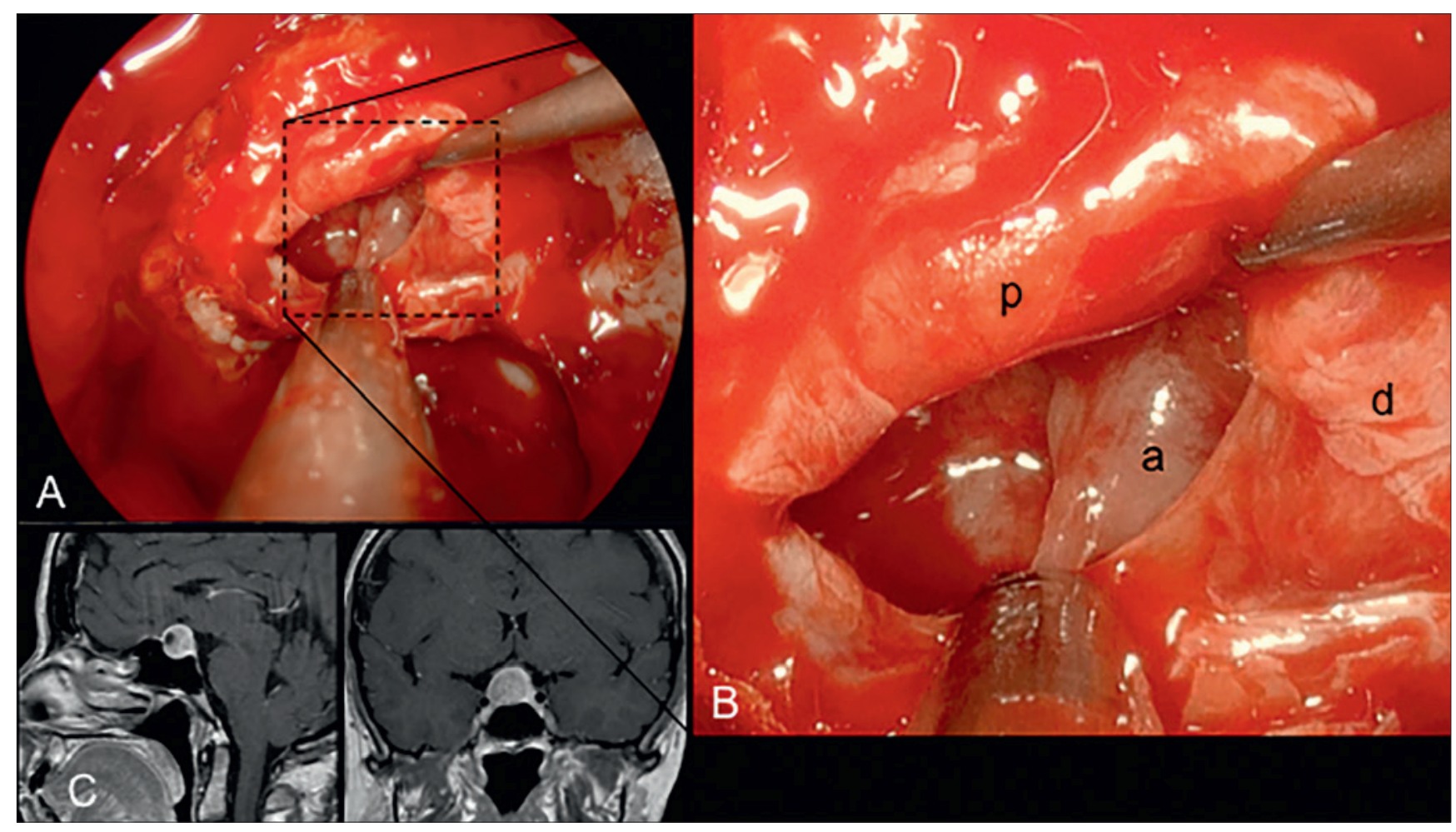

Fig. 1. Endoscopic view (A) of the sellar phase using the $4 \mathrm{~K}$ Olympus endoscope in a case of not secreting macroadenoma as observed in MRI (C). The magnified view (B) allowed a correct discrimination of the details and chromatic differences between normal pituitary (p) tissue versus adenoma (a) the different layers of dura (d) and the texture of the pathologic tissue. 


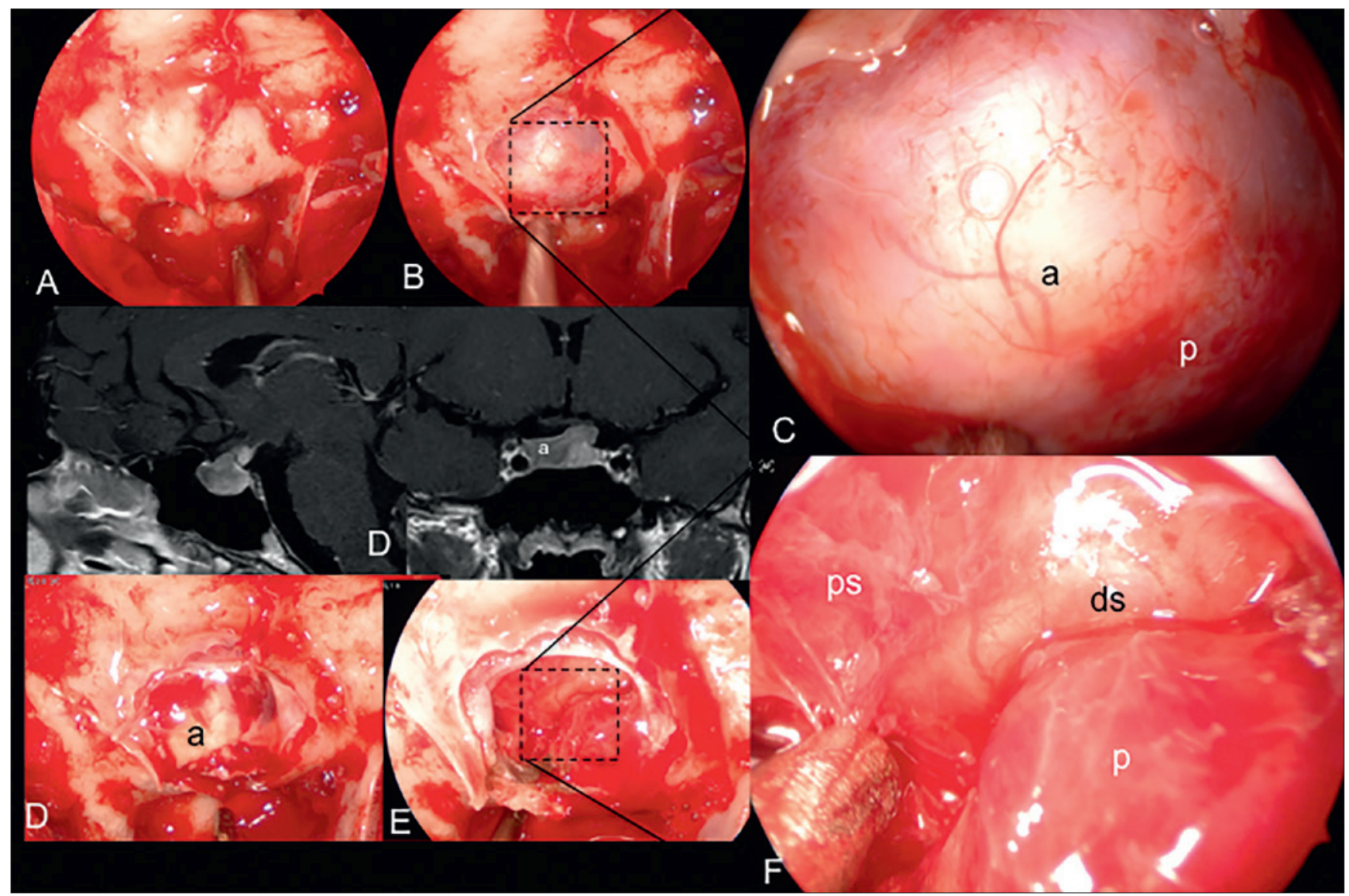

Fig. 2. Endoscopic view (A) of the sellar phase using the 4K Olympus endoscope in a case of GH secreting macroadenoma as showed in the MRI (D). The magnified view allowed a correct discrimination of the details and chromatic differences between normal pituitary tissue versus adenoma, starting from the initial phases before opening the dura (B-C). After tumour removal the great detailed resolution allowed the correct evaluation of the normal pituitary gland ( $p$ ), the meningohypophiseal arteries and the pituitary stalk (ps) leading to a complete removal of the pathologic tissues and exposure of the dura of the dorsum sellae (ds).

Among the minor disadvantages, important to comment upon, we found during our surgical procedures were: 1) an dedicate colour combination setting that had a very huge role in the red colour discrimination, especially during a bleeding within the sellar space; 2 ) the $4 \mathrm{~K}$ video and image storage needs a lot of space to build up a archive and a dedicated storage and registration unit is of paramount importance even if this is not inexpensive; 3 ) the use of 55' monitor requires a lot of space in the operating room to have a correct distance for good visualisation.

Fortunately, we acquired all the video with this tool but the user will also need a updated computer in order to visualise and mount videos, but the final result is very impressive in terms of resolution. $4 \mathrm{~K}$ endoscope combined with NBI technology ${ }^{4}$ has in our opinion the potential to start a revolution in skull base surgery, even if Akutsu used a flexible scope and standard HD monitor after re- moval of pituitary adenoma to check if there is still pathology in a series of 25 cases ${ }^{5}$.

Further studies using the same NBI technology combined with $4 \mathrm{~K}$ resolution and rigid scope are necessary to validate this extremely interesting potential. Surgery was successfully completed in all 22 cases and the new device shows promising features. This preliminary experience suggests that UHD endoscopy has a great potential going farther than the mere technical specifications might suggest. The visualisation and high resolution of the operative field provided a very detailed view of all anatomical and pathological structures leading to an improvement of safety and efficacy of the surgical procedure. The operative time was similar to the standard 2D $\mathrm{HD}$ and $3 \mathrm{D}$ procedures and the physical strain was also comparable to the latter techniques in terms of ergonomics and weight. 


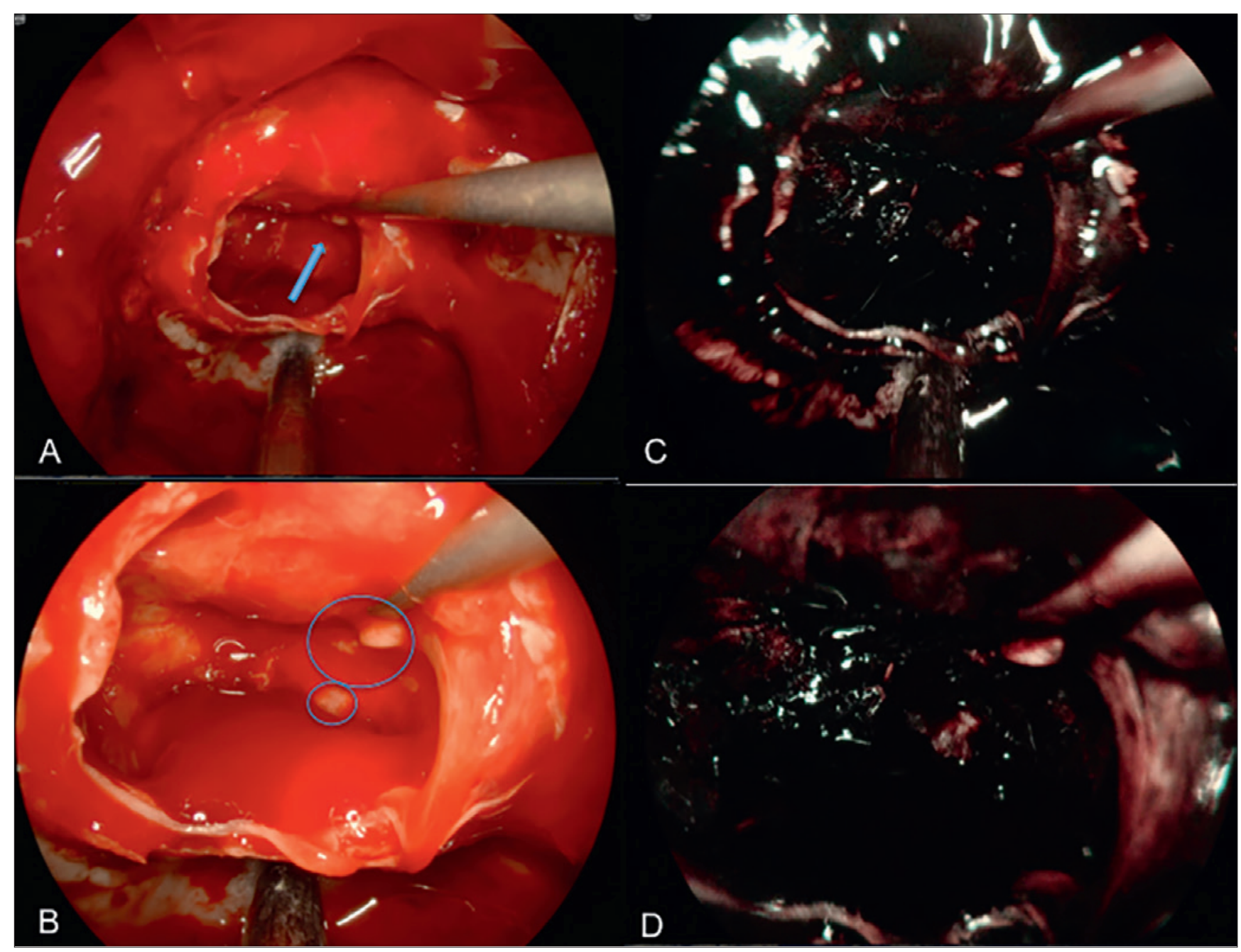

Fig. 3. Endoscopic view of the field after complete removal of the macroadenoma (A) showing the suspect quite small residual disease (arrows and circles) that clearly appears with magnification at high resolution (B) but seems to be confirmed using NBI filter (C,D), even if further experience and studies are necessary.

\section{References}

1 Maier H, de Heer G, Ortac A, et al. Capturing and displaying microscopic images used in medical diagnostics and forensic science using $4 K$ video resolution - an application in higher education. J Microsc 2015;260:175-9.

2 Felisati G, Lenzi R, Pipolo C, et al. Endoscopic expanded endonasal approach: preliminary experience with the new $3 D$ endoscope. Acta Otorhinolaryngol Ital 2013;33:102-6.

3 Cappabianca P., Cavallo LM, Esposito F, et al. Endoscop- ic endonasal transsphenoidal surgery: procedure, endoscopic equipment and instrumentation. Childs Nerv Syst 2004;20:796-801.

4 Arens C, Betz C, Kraft M,et al. Narrow band imaging for early diagnosis of epithelial dysplasia and microinvasive tumors in the upper aerodigestive tract. HNO 2017;65(Suppl 1):5-12.

5 Akutsu N, Taniguchi M, Kohmura E. Visualization of the normal pituitary gland during the endoscopic endonasal removal of pituitary adenoma by narrow band imaging. Acta Neurochir (Wien) 2016;158:1977-81. 